\title{
Neonatal treatment with 6-OH-DA affects brain NE content but not behavior
}

\author{
R. L. ISAACSON, W. J. STREET, T. L. PETIT, and A. J. DUNN \\ University of Florida, Gainesville, Florida 32611
}

\begin{abstract}
Two groups of neonatal rats were administered 6-hydroxydopamine to study the effects of catecholamine depletion on adult behavior. At about 6 weeks of age, the animals began training on a simple brightness discrimination task. They were subsequently tested for activity and reactivity in a Hebb-Williams maze and trained in a two-way active avoidance task. After sacrifice, brain assays indicated a substantial reduction in norepinephrine, but not dopamine, level. There were no statistical differences between 6-OH-DA-treated and control animals in the acquisition or final performance of the discrimination problem, nor were there differences between the groups on mean activity or reactivity scores. Performance in an active avoidance task also did not differentiate between treated and control rats.
\end{abstract}

Intracisternal or peripheral administration of 6OH-DA to newborn animals produces a marked reduction in brain catecholamine levels (Angeletti, 1971; Breese \& Traylor, 1971; 1972; Clark, Laverty, \& Phelan, 1972; Lew \& Quay, 1971; Lytle, Shoemaker, Cottman, \& Wurtman, 1972). However, there is some uncertainty about the duration of the effects produced by 6-OH-DA in the central nervous system. For example, there is no resolution of conflicting results obtained by competent workers in the field. Bloom (1971), Iverson and Uretsky (1971), and Ungerstedt (1971) are examples of those who found permanent (up to 2 years) depletion of CA levels after administration of 6-OH-DA, while Bartholini, Thoenen, and Pletscher (1971) and Richards (1971) found only transient changes with subsequent recovery of the catecholamine system.

Following the destruction of central catecholamine (CA) containing fibers in developing rats, decrements have been found in eating, drinking, and intake of sucrose solution (Smith, Cooper, \& Breese, 1973) and there has been a marked deficiency in body growth (Breese \& Traylor, 1972; Traylor \& Breese, 1971). Animals treated with 6-OH-DA in infancy have been reported to be less active in a Y-maze when compared with controls (Clark et al., 1972) but not different from controls in an open field (Pappas \& Sobren, 1972) or Y-maze (Taylor, Clark, Laverty, \& Phelan, 1972). Smith et al. (1973) noted that the behavioral effects of infant 6-OH-DA injections depend on the dose level of the drug used and the relative decrease in dopamine (DA) and norepinephrine (NE) levels in the brain. They observed that chemical lesions that preferentially decrease NE levels relative to DA result in increased locomotor activity in a circular apparatus measured by the interruption of light beams. Injection of 6-OH-DA at dose levels that result in large decreases in both NE and DA brain levels resulted in decreased exploratory activity.
Decreases in rearing and grooming during openfield tests (Ellison \& Bresler, 1974) have been observed after depletion of CA early in life. Ellison and Bresler also found an exaggerated decrease in activity when flashing lights and intermittent noise were introduced in the open field. They found no differences in shock-elicited aggression or in reactions to quinine. The 6-OH-DA-treated animals showed more spontaneous shuttle crossings when first placed in a shuttlebox, but the animals became less active than controls when training began. No differences were found in their shuttlebox performance to escape bright lights.

One learning task that animals with depletion of CA by 6-OH-DA early in life have been tested on is a two-way avoidance problem. Smith et al. (1973) found a decrement in performance of 6-OH-DAtreated animals in their ability to improve performance during acquisition of a shuttlebox avoidance response. In this study, we undertook to evaluate the effects of CA depletion accomplished early in life by the administration of 6-OH-DA in several behavioral tasks with the hope of gaining knowledge about the range of behaviors affected by the treatment.

\section{METHOD}

Two groups of rats were involved in this study with the experimental procedures for the second group basically the same as those for the first group. The groups will be called A and B. Differences found between the groups will be described below.

\section{Subjects}

Group A consisted of nine Long Evans hooded rats, five females and four males, born in a laboratory colony from stock obtained from the Charles River Breeding Laboratory. The animals were littermates. The 13 Group $B$ rats, seven females and six males, were from the same stock as Group $A$ and were also littermates. 


\section{Equipment}

The magazine training and brightness discrimination problems were done in Lehigh Valley Electronics two-bar operant chambers. A Hebb-Williams (1946) maze was used to obtain activity and reactivity measures. The maze is $76.2 \mathrm{~cm}$ long $\times 76.2 \mathrm{~cm}$ wide $\times$ $20.32 \mathrm{~cm}$ high and is divided into 36 equal squares. Movable wooden barriers were used to form the particular maze configuration being studied. Data were also collected on the animals while performing in a standard two-way active avoidance chamber.

\section{Procedures}

All animals were injected subcutaneously with $300 \mathrm{mg} / \mathrm{kg}$ 6-OH-DA or $0.1 \mathrm{ml}$ saline on postnatal Days 2 and 3. Five animals from Group A and six animals from Group B received 6-OH-DA. The remainder received saline. The infants were allowed to mature undisturbed until weaning (postnatal Day 23), at which time they were separately housed.

On postnatal Day 42, Group A animals were placed on a $231 / 2-h$ water-deprivation schedule. The animals were allowed access to water for $1 / 2 h$ after each day's session. They were maintained on this schedule through the first portion of testing on the activity task. Water deprivation began for the Group B animals on postnatal Day 38.

On Day 45, Group A rats were begun on a continuous reinforcement schedule for water reward contingent on barpressing. This was begun for Group B on Day 40. When the animals reached proficiency in barpressing, they began training on the visual discrimination task. This problem required the animals to press the lever which had a small light over it and not to press the lever without the light. A water reinforcement was given for correct responses (see Woodruff and Isaacson, 1972, for further details of the training apparatus and procedure). Group A began on Day 54 and Group B began on Day 51 .

After all animals had been trained on the brightness discrimination, they were tested for activity in a Hebb-Williams maze. The maze configuration was Hebb and William's maze No. 6 (1946). This configuration was chosen because it is one of the most complex, allowing a large number of culs for activity and exploration. Group A began testing on Day 155 and Group B on Day 165. Activity measures were taken for 3 days for Group $A$ and 4 days for Group B. The number of squares crossed by each rat during a 5-min period was noted and used as the measure of locomotor activity. The animals were then given access to water, and activity measures were collected for 4 additional days for Group $A$ and for 3 additional days for Group B. At the end of this time, while the rats were still water satiated, a reactivity measure was made on all of the rats. The same procedure used for the activity measure was employed, but additional white noise at $65 \mathrm{~dB}$ was produced by the ventilating fans from two operant chambers $2 \mathrm{~m}$ away for $5 \mathrm{sec}$ at the beginning of the $5 \mathrm{~min}$ in the maze.

Finally, the animals were trained in a two-way active avoidance task similar to that used by Smith et al. (1973). At the end of training, the animals were sacrificed by guillotine and the brains processed by the methods of Anton and Sayre $(1962,1964)$ for determination of NE and DA levels.

\section{RESULTS}

The results of the animal brain assays indicated a substantial reduction $(58 \%)$ of total NE level, but not of DA level (105\%), as a result of the 6-OH-DA treatment. The mean value of micrograms/gram of NE per brain tissue for the control animals was 380 as compared to 219 for the 6-OH-DA-treated animals. The mean values for DA were $612 \mu \mathrm{g} / \mathrm{g}$ for the controls and $640 \mu \mathrm{g} / \mathrm{g}$ for the 6-OH-DA-treated rats.

\section{Operant Discrimination Task}

No differences were found between the treated and untreated groups in the ease with which barpress responding was acquired, but there was a difference in the number of responses made during preliminary training on a continuous reinforcement schedule (CRF), with the 6-OH-DA-treated animals making more responses than the control animals. There were also differences in the average rate of responses between the two litters of subjects (Groups A and B), probably related to slightly different shaping procedures used to get the animals to barpress in the operant chambers. Considering the total responses made on the last 4 days of CRF training, the mean number of barpresses of the control and treated animals were 457.40 and 717.25 , respectively, in Group A, while the means of the control and treated animals in Group B were 809.67 and 1,316.29, respectively. The number of responses made by animals in each group were rank-ordered and divided at the median. The frequency of treated and nontreated animals falling above or below the median in the treatment and control groups were combined and statistically evaluated by the exact chi-square method $(p=.03)$.

There were no differences between the groups in the acquisition of the visual discrimination problem or in the final levels of performance. All animals acquired the problem to near $100 \%$ performance (see Figure 1). There were no differences in the number of responses made in the 10 -sec time-out periods that occurred after every press of one of the two bars. These were tabulated separately for time-out periods after correct and incorrect responses, but no differences were found between the groups in the number of time-out responses in either category.

\section{Activity and Reactivity Measures}

Although the control animals crossed more squares than the treated animals in all three situ-

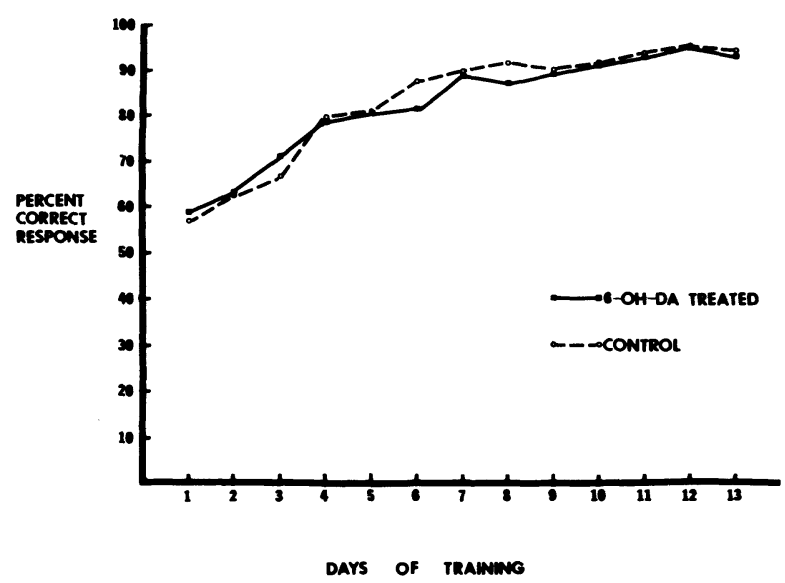

Figure 1. Percent correct responses of the 6-OH-DA-treated and untreated animals during training on the visual discrimination problem. 
Table 1

Means of the Activity Measure While Water Deprived and Satiated and the Reactivity Measure While Satiated

\begin{tabular}{lcccc}
\hline Groups & N & $\begin{array}{c}\text { Activity } \\
\text { Deprived }\end{array}$ & $\begin{array}{c}\text { Activity } \\
\text { Satiated }\end{array}$ & $\begin{array}{c}\text { Reactivity } \\
\text { Satiated }\end{array}$ \\
\hline 6-OH-DA & 11 & 74.6 & 89.0 & 90.8 \\
Control & 11 & 83.9 & 94.8 & 91.6 \\
\hline
\end{tabular}

ations, there were no significant differences between the mean activity of reactivity scores for the control and 6-OH-DA-treated animals as determined by $t$ tests (see Table 1). The activity data was also examined by a three-factor two-repeated-measures (treatment; satiated or water deprived; number of trials) analysis of variance (Dixon, 1974). The only statistically significant factor was a main effect of level of water deprivation $(F=8.13, \mathrm{df}=1 / 20$, $\mathrm{p}<.01)$. As can be seen from Table 2 , both groups of rats were more active when water-satiated than when water-deprived. An analysis of variance was also performed on the reactivity measure. No significant differences were found.

\section{Active Avoidance Training}

Because the training began with the animals being given an electrical footshock on the first trial, several animals in both groups exhibited escape responses to the buzzer (responses made before the end of the 10 -sec CS-US interval). It is possible that the 6-OHDA treatment could have differentially affected this aspect of performance. Therefore, the data were analyzed by considering the trial of the first avoidance response, the number of trials in which the animals responded to the CS itself before having had an "escape trial," the trial of the first avoidance response after the animal had stopped responding to the CS alone, and the trial at which the animal began blocks of 10 trials in which eight and nine correct avoidance responses were made. The mean scores are given in Table 2 . Four control animals and two 6-OH-DA animals failed to acquire the problem, and their data are not presented in the table.

Even though the means of the 6-OH-DA-treated animals are lower than those of the control groups, no statistical differences were found between the

Table 2

The Means of the Trial of the First Avoidance Response (1st Avoid), the Number of Trials on Which a Response Was Made After the CS in Less than 10 Sec (Sensitization Trials), the Trial of the First Avoidance Response After the Sensitization Period (1st Avoid After), the Trial that Began a Block of 10 Trials that Contained 8 Avoidance Responses (8/10), and the Trial that Began a Block of 10 Trials that Contained 9 Avoidance Responses (9/10)

\begin{tabular}{lcccccc}
\hline \multicolumn{7}{c}{$\begin{array}{c}\text { Sensiti- } \\
\text { zation }\end{array}$} \\
Groups & 1st Avoid & 1st Avoid & Trials & After & $8 / 10$ & $9 / 10$ \\
\hline 6-OH-DA & 9 & 4.56 & 3.11 & 10.33 & 37.78 & 40.00 \\
Control & 7 & 6.85 & 11.14 & 18.60 & 52.29 & 55.86 \\
\hline
\end{tabular}

groups using either parametric or nonparametric procedures. While not reported in the table, an analysis was also done of the number of footshocks received before learning the problem to either the 8 of 10 or 9 of 10 performance criterion. No differences were found between the groups.

\section{DISCUSSION}

The failure of the neonatal administration of 6-OH-DA to influence acquisition or performance of the behavioral problems may seem to stand in contrast to the work of others that have reported deficiencies following 6-OH-DA treatments. However, it should be noted that Cooper, Breese, Howard, and Grant (1972) and Smith et al. (1973) have presented evidence supporting the view that it is the reduction of DA by intracisternal administration of 6-OH-DA into adult rats that is responsible for alterations found in avoidance tasks. Howard, Grant, and Breese (1974) report substantial correlations between DA remaining in the brain after 6-OH-DA treatment and acquisition and sustained performance in a T-maze problem for a food reward, but they found no correlation between remaining brain NE and performance. In the present study, the 6-OH-DA treatment did not affect DA, but did affect NE levels. DA level after treatment seems to be related not only to the performance of learned reactions but also to locomotor performance (Hollister, Breese, \& Cooper, 1974). Since we failed to find alterations in locomotor behavior in our animals with NE but not DA depletion, this would support the importance of the latter catecholamine for this form of behavior as well.

The selective and permanent reduction in brain $\mathrm{NE}$ is similar to the results Zieher and Jaim-Etcheverry (1973) obtained from the neonatal peripheral administration of 6-OH-DOPA, a drug that is decarboxylated to 6-OH-DA in the brain. These authors also failed to find any effect of the treatment on DA or 5-HT levels when measured in adulthood. Sachs and Jonsson (1975) have also found that doses larger than $10 \mathrm{mg} / \mathrm{kg}$ administered peripherally to neonatal rats produce prolonged reductions of forebrain NE and decreased NE uptake. They report that permanent reduction of forebrain NE occurred only when effective doses were given before 7 days of age, presumably before the development of the blood-brain barrier. With lower doses of 6-OH-DA or administration after 7 days postnatally, recovery of NE levels and a return to normal uptake was observed. The question of possible recovery of normal $\mathrm{NE}$ activity is important since it has been suggested that those animals that exhibit partial recovery from 6-OH-DA treatment are the most behaviorally changed (Sorenson \& Ellison, 1973). The failure to find behavioral effects of the 6-OH-DA treatment 
in the present study may also be related to the failure of the animals to regain normal NE levels over the course of development.

\section{REFERENCES}

ANgeletti, P. N. Chemical sympathectomy in newborn animals. Neuropharmacology, 1971, 10, 55-59.

Anton, A. M., \& SAYre, D. F. A study of the factors affecting the aluminum oxide-trihydroxyindole procedure for the analysis of catecholamines. Journal of Pharmacology and Experimental Therapeutics, 1962, 138, 360-375.

Anton, A. H., \& SAYRe, D. F. The distribution of dopamine and DOPA in various animals and a method for their determination in diverse biological material. Journal of Pharmacology and Experimental Therapeutics, 1964, 145, 326-336.

Bartholini, G., Thoenen, H., \& Pletscher, A. Biochemical effects of 6-hydroxydopamine in brain without detectable ultrastructural changes. In T. Malmfors \& H. Thoenen (Eds.), 6-Hydroxydopamine and catecholamine neurons. New York: American Elsevier, 1971. Pp. 163-170.

BLоoм, F. E. Fine structural changes in rat brain after intracisternal injection of 6-hydroxydopamine. In T. Malmfors \& $\mathrm{H}$. Thoenen (Eds.), 6-Hydroxydopamine and catecholamine neurons. New York: American Elsevier, 1971. Pp. 135-150.

Breese, G. R., \& Traylor, T. D. Depletion of brain noradrenaline and dopamine by 6-hydroxydopamine. British Journal of Pharmacology, 1971, 42, 88-89.

Breese, G. R., \& Traylor, T. D. Developmental characteristics of brain catecholamines and tyrosine hydroxylase in the rat: Effects of 6-hydroxydopamine. British Journal of Pharmacology, 1972, 44, 210-222.

Clark, D. N., Laverty, J. R., \& Phelan, E. L. Long-lasting peripheral and central effects of 6-hydroxydopamine in rats. British Journal of Pharmacology, 1972, 44, 831-842.

Cooper, B. R., Breese, G. R., Howard, J. L., \& Grant, L. D. Effect of central catecholamine alterations by 6-hydroxydopamine on shuttlebox avoidance acquisition. Physiology and Behavior, 1972, 9, 727-731.

Dixon, W. J.Biomedical computer programs. Berkeley: University of California Press, 1974. (BMD08V).

Ellison, G. D., \& Bresler, D. E. Tests of emotional behavior in rats following depletion of norepinephrine or serotonin, or of both. Psychopharmacologia, 1974, 34, 275-288.

HeBb, D. O., \& Williams, K. A method of rating animal intelligence. Journal of General Psychiatry, 1946, 34, 59-65.

Hollister, A. S., Breese, G. R., \& Cooper, B. R. Comparison of tyrosine hydroxylase and dopamine-B-hydroxylase inhibition with the effects of various 6-hydroxydopamine treatments on amphetamine induced motor activity. Psychopharmacologia, 1974, 36, 1-16.

Howard, J. L., Grant, L. D., \& Breese, G. R. Effects of intracisternal 6-hydroxydopamine treatment on acquisition and per- formance of rats in a double T-maze. Journal of Comparative and Physiological Psychology, 1974, 86, 995-1007.

IVERSEN, L. L., \& URETSKY, N. J. Biochemical effects of 6-hydroxydopamine on catecholamine-containing neurones in the rat central nervous system. In T. Malmfors \& $\mathrm{H}$. Thoenen (Eds.), 6-Hydroxydopamine and catecholamine neurons. New York: American Elsevier, 1971. Pp. 171-186.

LEw, G. M., \& QuAY, W. G. Noradrenaline contents of hypothalamus and adrenal gland increased by postnatal administration of 6-hydroxydopamine. Research Communications Chemical Pathology and Pharmacology, 1971, 2, 807-812.

Lytle, L. D., Shoemaker, W. J., Cottman, X., \& Wurtman, R. J. Longterm effects of 6-OH-DA treatment on tissue catecholamine levels. Journal of Pharmacology and Experimental Therapeutics, 1972, 183, 56-64.

Pappas, B. A., \& Sobren, S. K. Neonatal sympathectomy by 6-OH-DA in the rat: No effects of behavior but changes in endogenous brain NE. Life Science, 1972, 11, 653-659.

RichaRDs, J. G. Ultrastructural effects of 6-hydroxydopamine on catecholamine-containing neurons in the rat brain. In $T$. Malmfors \& H. Thoenen (Eds.), 6-Hydroxydopamine and catecholamine neurons. New York: American Elsevier, 1971. Pp. 151-162.

SACHS, C., \& Jonsson, G. Effects of 6-hydroxydopamine on central noradrenaline neurons during ontogeny. Brain Research, 1975, 99, 277-291.

Smith, R. D., Cooper, B. R., \& Breese, G. R. Growth and behavioral changes in developing rats treated intracisternally with 6-hydroxydopamine: Evidence for involvement of brain dopamine. Journal of Pharmacology and Experimental Therapeutics, 1973, 185, 609-619.

Sorenson, C. A., \& Ellison, G. D. Nonlinear changes in activity and emotional reactivity scores following central noradrenergic lesions in rats. Psychopharmacologia, 1973, 32, 313-325.

Taylor, K. M., Clark, D. W. J., Laverty, R., \& Phelan, E. L. Specific noradrenergic neurons destroyed by 6-OH-DA injection into newborn rats. Nature, New Biology, 1972, 239, 247-248.

TraYlor, T. D., \& BREESE, G. R. Effect of 6-hydroxydopamine (6-OH-DA) on brain tyrosine hydroxylase and growth of the developing rat. Federation Proceedings, 1971, 30, 334.

UNGERSTEDT, U. Nistochemical studies on the effect of intracerebral and intraventricular injections of 6-hydroxydopamine monoamine neurons in the rat brain. In $\mathrm{T}$. Malmfors \& $\mathrm{H}$. Thoenen (Eds.), 6-Hydroxydopamine and catecholamine neurons. New York: American Elsevier, 1971. Pp. 101-128.

WoodrufF, M. L., \& IsAacson, R. L. Discrimination learning in animals with lesions of hippocampus. Behavioral Biology, 1972, 7, 489-501.

ZiEhER, L. M., \& JAIM-ETChEVERRY, G. Regional differences in the long-term effect of neonatal 6-hydroxydopa treatment on rat brain noradrenaline. Brain Research, 1973, 60, 199-207.

(Received for publication August 17, 1976; revision accepted November 3,1976 .) 